\title{
TRANSPOR IODIN MELALUI MEMBRAN KLOROFORM DENGAN \\ NATRIUM TIOSULFAT SEBAGAI FASA PENERIMA DALAM TEKNIK MEMBRAN CAIR FASA RUAH
}

\author{
Refinel, Djufri Mustafa, Reni Fitriani \\ Fakultas Matematika dan Ilmu Pengetahuan Alam, Universitas Andalas, Padang 25163 \\ email: nafirefinel21@yahoo.com
}

\begin{abstract}
Iodine transport throught bulk liquid membrane technique consist of $10 \mathrm{~mL} \mathrm{I}_{2} / \mathrm{KI} 4 \times 10^{-3} \mathrm{~N}$ solution as donor phase, $20 \mathrm{~mL} \mathrm{Na} \mathrm{S}_{2} \mathrm{O}_{3} 0.02 \mathrm{~N}$ solution as reagent striping in acceptor phase, and $30 \mathrm{~mL}$ chloroform as membrane phase. Technical operation use magnetic stirring at 100 rpm. Concentration of iodine in donor phase and acceptor phase determined by Spectrophotometer UV-Vis $\lambda \max$ at $567 \mathrm{~nm}$. The results concluded that the optimum conditions of iodine transport $4 \times 10^{-3} \mathrm{~N}$ with $\mathrm{pH} 7$ in donor phase, comparison $\mathrm{I}_{2}: \mathrm{KI}$ in donor phase (1:5), and a long stirring is 120 minutes. The bulk liquid membrane technique with $\mathrm{Na}_{2} \mathrm{~S}_{2} \mathrm{O}_{3}$ as reagent striping in acceptor phase is potential for iodine transport from donor phase to acceptor phase with $86.71 \%$ of iodine transport. Fluxs values (transport rate) generated by using chloroform membrane of $1.8872 \times 10^{-7} \mathrm{~L} \mathrm{~cm}^{2}$. menit ${ }^{-1}$ at a maximum transport time of 120 minutes.
\end{abstract}

Keywords: Transport Iodine, Bulk Liquid Membrane Technique, Sodium Thiosulphate

\section{PENDAHULUAN}

Dampak negatif dari limbah iodin salah satunya ditemukan di rumah sakit. Iodin biasanya dipakai secara berlebihan terutama pada proses operasi, sehingga di lingkungan rumah sakit sering ditemukan limbah cair yang mengandung senyawa iodin ${ }^{[1]}$. Untuk itu diperlukan solusi dalam menanggulangi pencemaran ini.

Penelitian untuk memonitor dan memisahkan iodin yang terlarut dalam air sudah dilakukan oleh Betsabe, dkk dengan metoda membran cair fasa ruah. Iodin yang terlarut dalam air sebagai fasa sumber dengan cara memindahkan (mentranspor) iodin $\left(\mathrm{I}_{2} / \mathrm{KI}\right)$ melalui membran berupa minyak tanah (kerosin) ke fasa berair lain yang mengandung larutan $\mathrm{Na}_{2} \mathrm{~S}_{2} \mathrm{O}_{3}$ sebagai fasa penerima. Dari hasil penelitiannya di dapatkan waktu transpor iodin ke fasa penerima mencapai waktu yang cukup lama 28 jam dengan persen transpor $85 \%{ }^{[2]}$.

1. Penataan ulang dan memodifikasi sistem transpor diatas dengan memanfaatkan kelarutan iodin dalam kloroforom $(\mathrm{Kd}=340)$ sebagai fasa membran dengan beberapa jenis reagen aseptor (striping) sebagai fasa penerima penelitiannya telah dilakukan.

3. Jumlah iodin yang sampai ke fasa penerima sangat dipengaruhi oleh jenis reagen aseptor dalam fasa penerima. Pada penelitian ini diuji kemampuan reagen sebagai akseptor dalam fasa penerima, hasilnya dapat dilihat dalam Tabel 1.

Dari data dalam tabel menujukkan bahwa vitamin $\mathrm{C}$ mempunyai potensi yang sangat besar sebagai akseptor dalam fasa penerima dibandingkan reagen aseptor $\left(\mathrm{Na}_{2} \mathrm{SO}_{3}+\right.$ $\mathrm{NaOH})$ dan $\mathrm{Na}_{2} \mathrm{~S}_{2} \mathrm{O}_{3}$. 
Tabel 1. Data pengaruh jenis reagen aseptor di fasa penerima terhadap transpor iodin

\begin{tabular}{ccccc}
\hline No. & FS stripping & \multicolumn{3}{c}{$\%$ iodin } \\
\cline { 3 - 5 } & & FS sumber & FS membran & FS penerima \\
\hline 1. & $\mathrm{Na}_{2} \mathrm{SO}_{3}+\mathrm{NaOH}$ & 10,05 & 81,42 & 8,53 \\
2. & $\mathrm{Vitamin}_{\mathrm{C}}$ & 9,90 & 0,27 & 89,83 \\
3. & $\mathrm{Na}_{2} \mathrm{~S}_{2} \mathrm{O}_{3}$ & 15,49 & 16,33 & 68,18
\end{tabular}

Kondisi Percobaan : Fasa sumber $10 \mathrm{~mL}\left(\mathrm{I}_{2} / \mathrm{I}^{-}\right) \mathrm{pH}$ 3, fasa membran $30 \mathrm{~mL}$ kloform, fasa penerima $20 \mathrm{~mL}$, waktu transpor 1 jam dan waktu kesetimbangan 10 menit

Penelitian optimasi sistem transpor dengan menggunakan larutan Vitamin C sebagai fasa aseptor,iodin tertranspor $90,84 \%$ ke fasa penerima dalam waktu 90 menit, sedangkan untuk campuran larutan $\mathrm{Na}_{2} \mathrm{SO}_{3}+\mathrm{NaOH}$ sebagai fasa aseptor, iodin tertranspor 78,58 $\%$ ke fasa penerima dalam waktu 180 menit, telah di teliti ${ }^{[3,4,5]}$.

Sejauh mana kemampuan iodin dapat ditranspor melalui proses difusi antar fasa dari larutan berair $\mathrm{I}_{2} / \mathrm{KI}$ sebagai fasa sumber ke dalam kloroform sebagai membran dan menuju fasa penerima larutan $\mathrm{Na}_{2} \mathrm{~S}_{2} \mathrm{O}_{3}$ dalam suasana netral dilakukan pengkajian lebih lanjut untuk diteliti dengan harapan transpor iodin dapat berjalan lebih cepat tidak selama peneliti sebelumnya

\section{METODOLOGI PENELITIAN}

\section{Pembuatan Larutan Fasa Sumber $\mathrm{I}_{2} / \mathrm{KI}$}

Ditimbang sejumlah $0,4150 \mathrm{~g} \mathrm{KI}(\mathrm{Mr}=166$ $\mathrm{g} / \mathrm{mol}$ ) dan dilarutkan dengan akuades ke dalam beaker gelas sambil larutan diaduk sampai semua KI larut. Ke dalam larutan KI yang homogen dilarutkan $\mathrm{I}_{2}$ sebanyak 0,1270 $\mathrm{g}(\mathrm{Mr}=254 \mathrm{~g} / \mathrm{mol})$ sedikit demi sedikit sambil terus diaduk dengan bantuan magnetik bar. Volume campuran kedua zat dicukupkan sampai $250 \mathrm{~mL}$ dengan penambahan akuades dan ditutup rapat untuk mencegah agar larutan $\mathrm{I}_{2} / \mathrm{KI}$ tidak menguap. Konsentrasi larutan distandarisasi dengan larutan Tiosulfat. Larutan fasa sumber untuk ditranspor diambil $10 \mathrm{~mL}$ dan diatur pHnya dengan menggunakan $\mathrm{HCl} 0,1 \mathrm{~N}$ dan $\mathrm{NaOH}$ $0,1 \mathrm{~N}$.

\section{Fasa Membran}

Fasa membran yang digunakan dalam penelitian ini adalah kloroform dengan jumlah $30 \mathrm{~mL}$. Transpor terjadi melalui proses difusi.

\section{Pembuatan Larutan Fasa Penerima}

Ditimbang sejumlah $0,2482 \mathrm{~g} \mathrm{Na}_{2} \mathrm{~S}_{2} \mathrm{O}_{3}(\mathrm{Mr}=$ $248,21 \mathrm{~g} / \mathrm{mol}$ ) dan dilarutkan dengan akuades ke dalam beaker gelas hingga volume larutan mencapai $250 \mathrm{~mL}$, kemudian larutan ini di standarisasi dengan larutan Kalium bikromat dengan metoda Iodometri ${ }^{[7]}$. Larutan fasa penerima ini diambil $20 \mathrm{~mL}$ dan $\mathrm{pH}$ yang digunakan netral ( $\mathrm{pH} 7)$.

\section{Penentuan Transpor Iodin Melalui Membran Cair Fasa Ruah.}

Percobaan transport dilakukan dengan memakai metoda Safavi ${ }^{[4,5,6,10,11,13]}$. Ke dalam beaker gelas $100 \mathrm{~mL}$ (diameter $4,8 \mathrm{~cm}$ ) dimasukan fasa membran kloroform $30 \mathrm{~mL}$, kemudian ke dalamnya dicelupkan sebuah tabung kaca silindris (diameter $3 \mathrm{~cm}$ ) yang ke dalamnya dipipetkan $10 \mathrm{~mL}$ larutan fasa sumber $\mathrm{I}_{2}$, $\mathrm{KI} 4 \times 10^{-3} \mathrm{~N}$ yang $\mathrm{pH}$ larutan telah diatur terlebih dahulu. Di luar tabung kaca silindris dipipetkan $20 \mathrm{~mL}$ larutan fasa penerima $\mathrm{Na}_{2} \mathrm{O}_{2} \mathrm{O}_{3} 8 \times 10^{-3} \mathrm{~N}$ dan juga telah di atur $\mathrm{pH}$ larutannya. Teknis operasi transport dilakukan melaui pengadukan dengan menggunakan magnetik stirrer pada kecepatan $100 \mathrm{rpm}$ selama 1 jam, proses transpor iodine berlangsung melalui difusi. Setelah pendiaman selama 10 menit, fasa sumber dan fasa penerima diambil untuk diukur konsentrasi iodin sisa dan yang berhasil tertranspor dengan alat spektrofotometer UV-Vis. 


\section{HASIL DAN PEMBAHASAN}

\section{Pengaruh pH dalam Fasa Sumber terhadap Transpor Iodin.}

Menurut Betsabe, dalam larutan air iodin akan terhidrolisis seperti reaksi berikut :

$$
\mathrm{I}_{2}+\mathrm{H}_{2} \mathrm{O} \quad \rightleftarrows \quad \mathrm{HIO}+\mathrm{I}^{-}+\mathrm{H}^{+}
$$

Oleh karena itu, dilakukan penelitian terhadap variasi $\mathrm{pH}$ larutan di fasa sumber dari $\mathrm{pH} 3 \mathrm{~s} / \mathrm{d} 7^{[1,14]}$. Difusi ini terjadi di antarmuka fasa sumber dan fasa membran dalam bentuk reaksi transisi berikut dan terjadi pada $\mathrm{pH}$ tertentu ${ }^{[5]}$ :

$$
\mathrm{I}_{2} / \mathrm{I}^{-}(\mathrm{aq}) \quad \mathrm{I}_{2 \text { (org) }}
$$

Dari kurva dalam Gambar 1, terlihat transpor antar fasa membran dengan fasa penerima cepat terjadi pada $\mathrm{pH}$ fasa sumber 7 , hal ini sesuai dengan kondisi reaksi yang terjadi antara $\mathrm{I}_{2}$ (aq) dengan $\mathrm{Na}_{2} \mathrm{~S}_{2} \mathrm{O}_{3}$ dari fasa penerima terjadi pada kondisi netral, dengan reaksi sebagai berikut : $:^{7]}$

$$
\mathrm{I}_{2}+2 \mathrm{~S}_{2} \mathrm{O}_{3}{ }^{2-} \rightleftarrows 2 \mathrm{I}^{-}+\mathrm{S}_{4} \mathrm{O}_{6}{ }^{2-}
$$

Pada $\mathrm{pH}$ kecil dari $7, \mathrm{I}_{2}$ terperangkap dalam membran cukup besar $\left(\mathrm{pH} \mathrm{3}, \mathrm{I}_{2}\right.$ dalam fasa membran $27,69 \%$ ). Secara visual terlihat fasa membran bewarna pink, hal ini disebabkan pada $\mathrm{pH}$ kecil reaksi $\mathrm{Na}_{2} \mathrm{~S}_{2} \mathrm{O}_{3}$ dalam fasa pemerima tidak maksimal untuk dapat menarik $\mathrm{I}_{2}$ keluar dari fasa membran.

\section{Pengaruh Perbandingan Konsentrasi $\mathbf{I}_{2}$ : KI di Fasa Sumber terhadap Transpor Iodin}

Ion iodida di dalam air membentuk reaksi yang setimbang sebagai berikut: $:^{[2,4,5,7]}$

$$
\mathrm{I}_{2}+\mathrm{I}^{-} \rightleftarrows \mathrm{I}_{3}^{-}
$$

Kesetimbangan reaksi kelarutan iodin ini dalam bentuk $\mathrm{I}_{3}{ }^{-}$merupakan dasar utama untuk mengekstrak iodin kedalam pelarut organik kloroform (fasa membran). Dalam hal ini perlu dicari kondisi yang tepat untuk mempermudah terjadinya proses transisi iodin terekstrak dari fasa sumber ke fasa membran kloroform dan kemudian ke fasa penerima, yakni dengan melakukan pengaturan perbandingan konsentrasi $\mathrm{I}_{2}$ dengan KI di fasa sumber. Konsentrasi larutan $\mathrm{I}_{2}$ di fasa sumber dibuat tetap yaitu 4 x $10^{-3} \mathrm{~N}$, sedangkan konsentrasi larutan $\mathrm{KI}$ divariasikan dalam bentuk perbandingan 1:1 s/d 1:7. Dari kurva dalam Gambar 2, menunjukan bahwa tranpor $\mathrm{I}_{2}$ optimal terjadi pada perbandingan fasa sumber $\mathrm{I}_{2} / \mathrm{KI}$ 1:5.

\section{Pengaruh Konsentrasi $\mathrm{Na}_{2} \mathrm{~S}_{2} \mathrm{O}_{3}$ di Fasa Penerima terhadap Transpor Iodin}

Konsentrasi pada fasa penerima sangat mempengaruhi hasil persen pencapaian $\mathrm{I}_{2}$ yang akan tertranspor ke fasa penerima. Kurva dalam Gambar 3, menunjukan $\mathrm{I}_{2}$ yang tertranspor ke fasa penerima terus meningkat mencapai $84,15 \%$ diperoleh pada konsentrasi larutan fasa penerima $\mathrm{Na}_{2} \mathrm{~S}_{2} \mathrm{O}_{3}$ adalah $0.02 \mathrm{~N}$. Namun pada konsentrasi diatas $0.02 \mathrm{~N}$ persen transpor sudah konstan dan iodin yang tersisa di fasa sumber tidak terdeteksi lagi. Sedangkan pada konsentrasi $\mathrm{Na}_{2} \mathrm{~S}_{2} \mathrm{O}_{3}$ kecil dari $0,02 \mathrm{~N}$ sebagai fasa penerima jumlah $\mathrm{Na}_{2} \mathrm{~S}_{2} \mathrm{O}_{3}$ belum cukup untuk dapat terjadi stripping $I_{2(\mathrm{og})}$ dengan sempurna dari fasa membran ke fasa penerima.

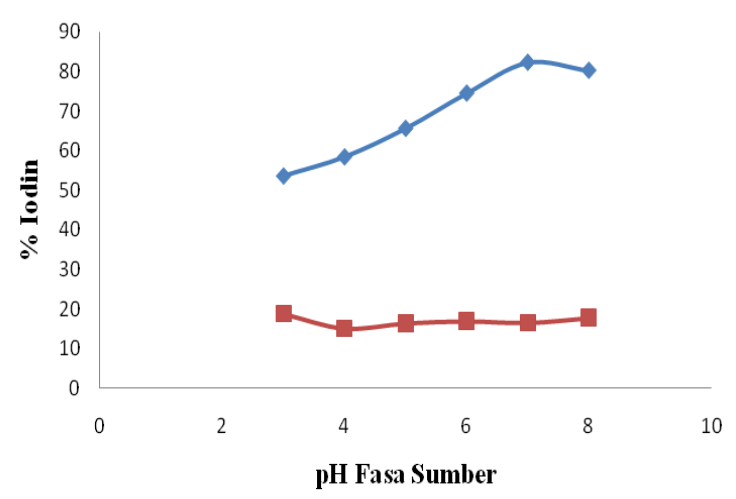

Gambar 1. Variasi $\mathrm{pH}$ larutan fasa sumber terhadap \% iodin yang diperoleh di fasa sumber ( $(\boldsymbol{\bullet})$ dan fasa penerima $(\bullet)$

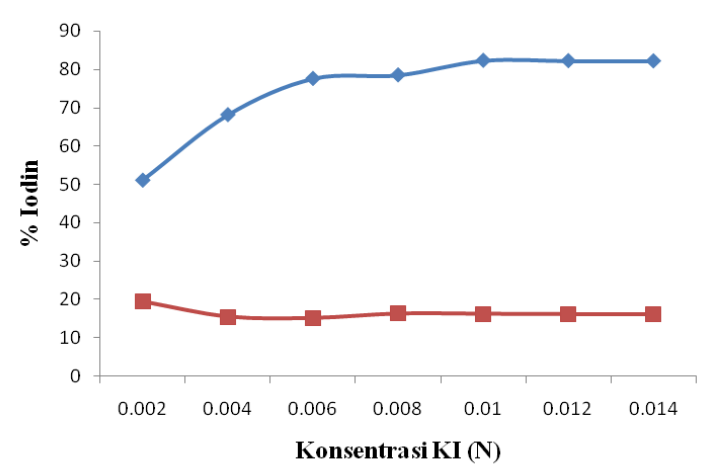

Gambar 2.Variasi Perbandingan Konsentrasi $\mathrm{I}_{2}$ : KI di Fasa Sumber terhadap \% iodin yang diperoleh di fasa sumber (a) dan fasa penerima $(\star)$ 


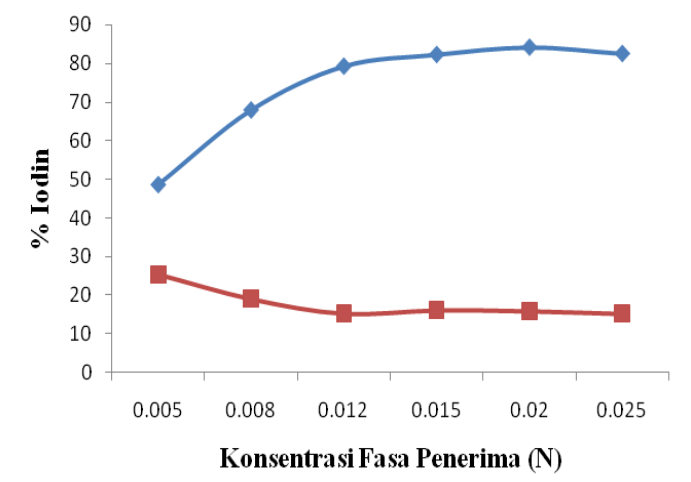

Gambar 3. Variasi Konsentrasi Fasa Penerima terhadap \% iodin yang diperoleh di fasa sumber ( $\bullet$ ) dan fasa penerima ( $\bullet$

\section{Pengaruh Waktu terhadap Transpor Iodin}

Pengaruh waktu transpor memberikan perubahan yang nyata terhadap sistim membran ${ }^{[8,9,12]}$.Secara visual proses transpor ini dapat diikuti yaitu pada waktu awal warna kuning iodin yang ada di fasa sumber semakin memucat dengan bertambahnya waktu transpor, sedangkan kloroform yang bertindak sebagai membran lama kelamaan akan berwarna pink/merah jambu pekat dan juga akan memudar kembali dengan bertambahnya waktu ${ }^{[2.3]}$. Namun, pada fasa penerima tidak mengalami perubahan warna selama proses transpor berlangsung. Persentase iodin yang berhasil tertranspor ke fasa penerima dalam waktu optimum 120 menit adalah sebesar $86,71 \%$. Reaksi yang terjadi adalah :
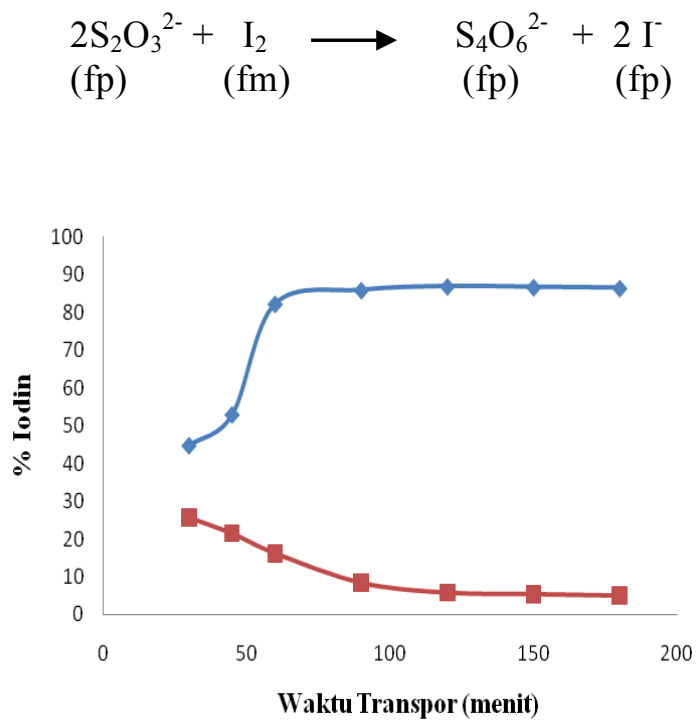

Gambar 4. Variasi Waktu Transpor terhadap $\%$ iodin yang diperoleh di fasa sumber (ロ) dan fasa penerima ( $\bullet)$

\section{KESIMPULAN}

5. Dari hasil penelitian yang telah dilakukan dapat disimpulkan bahwa transpor iodin melalui membran cair kloroform dan $\mathrm{Na}-$ ${ }_{2} \mathrm{~S}_{2} \mathrm{O}_{3}$ sebagai reagen stripping dalam fasa penerima dengan kecepatan pengadukan 100 rpm dapat mentranspor iodin secara optimal sampai ke fasa penerima dengan waktu transpor 120 menit (2 jam). Kondisi optimum untuk sistem transpor diperoleh pada $\mathrm{pH}$ larutan di fasa sumber 7, konsentrasi larutan fasa penerima (reagen stripping) adalah 0.02 $\mathrm{N}$, dan perbandingan konsentrasi KI yang digunakan untuk melarutkan $\mathrm{I}_{2}\left(\mathrm{I}_{2}: \mathrm{KI}\right)$ di fasa sumber adalah 1:5. Pada kondisi ini hasil transpor maksimal iodin diperoleh sebesar $86,71 \%$. Nilai fluk (laju transpor) yang dihasilkan dengan menggunakan membran kloroform sebesar 1,8872 x $10^{-7}$ $\mathrm{L} / \mathrm{cm}^{2}$ menit ${ }^{-1}$.

\section{DAFTAR PUSTAKA}

1. Samuel Finley," Pengelolaan Limbah Klinis Rumah Sakit," Tesis Pasca Sarjana UI (2004).

2. Nabieyan,A. Kargari, $\mathrm{T}$ Kaghazchi, A.Mahmoudian, M.Soleimani "BenchScale Pertraction of Iodine Using a Bulk Liquid Membrane System", Desalination (214) 167-176.

3. Departemen Kesehatan Republik Indonesia. "Farmakope Indonesia, edisi IV": Depkes RI. Hal 316-317 (2001).

4. Refinel, Imelda and Novas vania. Transpor Iodin Melalui Kloform dengan Vitamin C Sebagai fasa Akseptor Dalam Teknik membran Cair Fasa Ruah" Proseding Seminar Nasional HKI 1 (2013)197-202.

5. Refinel, Zaharasmi and Sukmawita, Transpor Iodin melalui membran Kloroform dengan Teknik Membran Cair Fasa Ruah. Jurnal Riset Kimia 5 (2011) $53-59$.

6. Savafi, and Shams. E. Selective and Efficient Transport of $\mathrm{Hg}(\mathrm{II})$ Through Bulk Liquid Membrane Using Methyl Red as Carrier. J. Membrane Sci 144 (1998) 37-43. 
7. Day. R. A and Under wood. A. L, Analisis Kimia Kuantitatif", Edisi VI, Airlangga. Jakarta, (2002).

8. Mulder, M., Basic Principle of Membran technology". Kluwer Academic Publisher, Dordrencht. pp. 244-259. (1991).

9. Refinel, Zaharasmi and Olly. Kinetika Transpor $\mathrm{Cu}(\mathrm{II})$ oleh zat pembawa Oksin dengan dan tanpa asam Oleat melalui membran cair fasa ruah. Jurnal Riset Kimia 2 (2009) 127 - 131.

10. Kahar Z., Mustafa D., and Wiwit. Kinetika dan Mekanisme Transpor Cd(II) Antar Fasa melalui Teknik Membran Cair Fasa Ruah Dengan Oksin Sebagai Zat pembawa. Jurnal Riset Kimia 1 (2007) 97 -100.

11. Refinel. Optimalisasi Transpor $\mathrm{Cu}(\mathrm{II})$ dengan Zat Pembawa Metil Merah
Melalui Teknik Membran Cair Fasa Ruah. Proseding Semirata FMIPA-Unja Jambi (2005) 17-19.

12. Refinel. Penentuan Kondisi Optimum Transpor Ion $\mathrm{Cd}(\mathrm{II})$ melalui Teknik Membran Cair Fasa Ruah secara Simultan dengan Oksin sebagai pembawa. Proseding Semirata FMIPA Unri Pekanbaru (2010).

13. Refinel, Zaharasmi and Olly. Kinetika dan Selektifitas Transpor Cu(II) antara fasa melalui membran Cair Fasa Ruah dengan Oksin sebagai zat pembawa. Jurnal Riset Kimia 4 (2010) 63-72.

14. Refinel. Optimasi Transpor Fenol melalui Membran Cair Kloform dalam Teknik Fasa Ruah, Proseding Seminar Nasional HKI PekanBaru (2011) 18-19. 